\title{
PROTOTIPE TUNGKU KRUSIBEL KOMPAK MINI
}

\author{
Arianto Leman S. ${ }^{1}$, Febrianto Amri R. ${ }^{1}$, Adiaksa Gilang P. ${ }^{1}$, Bima Y. ${ }^{1}$, Galang Dwi Z. ${ }^{1}$ \\ ${ }^{1}$ Jurusan Pendidikan Teknik Mesin FT UNY \\ Email: arianto_ls@uny.ac.id
}

\begin{abstract}
Crucible furnace for metal casting practice is needed by Vocational High School since their graduted students should posses competence in casting field. A prototype of mini compact crucible furnace is build as an effort to fulfiil needed of appropriate furnace. It is a sustain development of previous works. This furnace is developed using Research and development method. The prototype of mini compact crucible furnace that has been succeeded developed has dimension of (330x330x750) $\mathrm{mm}$ and $46 \mathrm{~kg}$ of total weight. The furnace can be made from used drum whith heat isolator combining of ceramic blanket D.96 and castable TNC-17. It is able to melt 3 $\mathrm{kg}$ of aluminium and achieve $660^{\circ} \mathrm{C}$ in 50 minute with LPG consumption of 1,76 kg. The outside temperature of the furnace is in safety limit while it is operated. However, the prototype of mini compact crucible furnace need further development to improve its performance and the heat effiency.
\end{abstract}

Keywords: Prototype, crucible furnace, compct, mini

\begin{abstract}
ABSTRAK
Tungku krusibel untuk praktik pengecoran logam dibutuhkan oleh Sekolah Menengah Kejuruan karena lulusannya harus memiliki komptensi dibidang pengecoran. Sebuah prototipe tungku krusibel mini dibuat sebagai upaya untuk memenuhi kebutuhan tungku yang sesuai. Ini merupakan pengembangan berkelanjutan dari tungkutungku sebelumnya. Prototipe tungku krusibel kompak mini dikembangkan dengan metode Reserach and Development. Prototipe tungku krusibel kompak mini yang berhasil dibuat berdimensi (330x330x750) mm dengan bobot total $46 \mathrm{~kg}$. Tungku dapat dibuat dari drum bekas dengan isolator panas kombinasi dari selimut keramik D.96 dan castable TNC-17. Prototipe tungku mampu melelehkan $3 \mathrm{~kg}$ aluminium dan mencapai suhu $660^{\circ} \mathrm{C}$ dalam 50 menit dengan kebutuhan LPG $1,76 \mathrm{~kg}$. Suhu dinding luar tungku masih dalam batas aman saat dioperasikan. Bagaimanapun, prototipe tungku krusibel kompak mini perlu dikembangkan lebih lanjut untuk memperbaiki kinerja dan efisiensi panasnya.
\end{abstract}

Kata kunci: Prototipe, tungku krusibel, kompak, mini

\section{PENDAHULUAN}

Praktik mengecor logam seyogyanya diselenggarakan oleh Sekolah Menengah Kejuruan (SMK) Kompetensi Keahlian Teknik Mesin. Ini merujuk pada SK Direktur Jenderal Pendidikan Menengah Kementerian Pendidikan dan Kebudayaan nomor: 06/D.DD5/KK/2018 tanggal 7 Juni 2018 tentang spektrum keahlian pendidikan menengah kejuruan. Aluminium adalah logam dengan suhu cair $660{ }^{\circ} \mathrm{C}$, mudah dituang dan banyak tersedia di pasaran. Oleh sebab itu, aluminium sesuai digunakan untuk praktik pengecoran logam di SMK. Model Laboratorium praktik pengecoran yang dapat diadopsi untuk praktik di SMK yang telah dikembangkan Arianto, dkk. (2017: 218-222) juga memanfaatkan aluminium.

Alat utama pada pembelajaran praktik pengecoran adalah tungku untuk mencairkan logam. Tungku dapat dibedakan atas sumber energi penghasil panas. Sumber energi tungku dapat berasal dari arang (Ighodalo, et.al., 2011: 448-450), minyak (Olalerel, et.al., 2015: 281288) atau gas (Chukwudi and Ogunedo. 2017: 13-21). Gas lebih menguntungkan untuk praktik pengecoran di SMK. Ini berdasarkan pada ketersediaan di pasar, energi panas yang tinggi, relatif murah, dan mudah diaplikasikan. Tungku pelebur dengan gas sebagai sumber energi panas telah dikembangkkan oleh Amir dan Akhyar (2013: 128-132), Abed (2013: 109- 
118), Alaya, dkk. (2016: 110-116); Chukwudi dan Ogunedo (2018: 67-74). Namun tungkutungku ini tidak ditujukan untuk praktik pengecoran di SMK.

Tungku pelebur untuk paktik pengecoan di SMK berbeda dengan tungku pelebur untuk produksi. Beberapa syarat harus dipenuhi untuk praktik di SMK Kompetensi Keahlian Teknik Mesin. Tungku konstruksinya harus sederhana dan ringkas, mudah dibuat, dipindah tempatkan, dioperasikan, dirawat, serta ringan, kapasitas memadai, waktu peleburan singkat, hemat energi, dan murah. Tungku yang memenuhi kriteria ini adalah tungku krusibel. Cirinya yaitu digunakan pot krusibel sebagai wadah logam yang dilebur. Pot ditemptkan pada dudukan didalam dasar tungku. Tungku krusibel untuk praktik yang telah dikemmbangkan atau didesain ulang juga memanfaatkan arang (Joko, 2013: 47-53), minyak (Eko, dkk., 2012: 24-30), ataupun gas (Ella, 2011: 17-26; Ikechukwu dan Atanmo, 2018: 1-14.) sebagai sumber enegi. Namun, tungku-tungku ini kurang sesuai untuk praktik di SMK karena kurang ringkas, berat, tidak mudah dipindah tempatkan, serta tidak mudah dioperasikan dan dirawat.

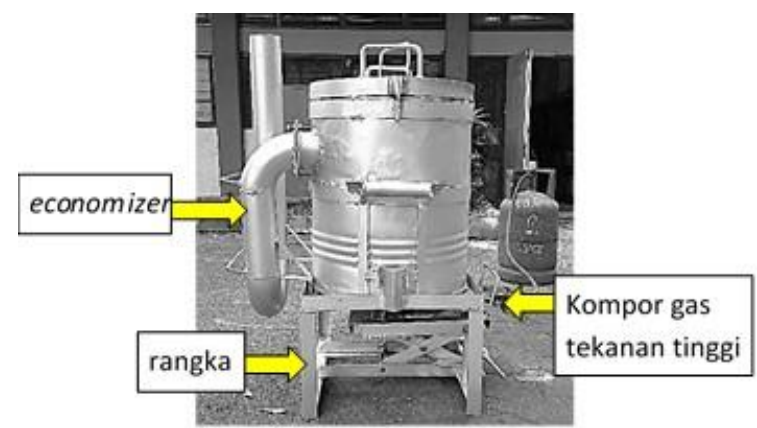

Gambar 1. Tungku krusibel kompak. (Arianto, dkk, 2017b: 279)

Arianto, dkk (2017a) telah membuat sebuah tungku pelebur untuk praktik pengecoran di SMK. Ini sebuah tungku krusibel yang disebut tungku krusibel kompak. Tungku ini ringkas dan kompak karena sumber panas dari sebuah kompor gas bertekanan tinggi ditempatkan tepat di bawah tungku, yaitu pada rangka penyangga tungku seperti tampak pada Gambar 1. Dimensi keseluruhan (460x460x900) mm dengan bobot total $129 \mathrm{~kg}$ dan berat tungku saja $89 \mathrm{~kg}$. Dalam 20-30 menit, $3 \mathrm{~kg}$ aluminium mulai meleleh di dasar kowi dan mencair seluruhnya dalam 50-60 menit dengan kebutuhan LPG 2-2,4 kg. Tungku ini sudah diterapkan di SMKN 3 Yogyakarta, SMK Muh 1 Salam dan SMKN 1 Magelang. (Arianto, dkk, 2017b: 277-284). Pada tahuntahun berikutnya, tungku diaplikasikan di SMKN 2 Wonosari dan SMK Muh 1 Playen, Gunungkidul serta SMK NU Ma'arif Kudus. Lebih jauh, Arianto, dkk (2018a, 2018b) secara berkesinambungan telah mengoptimalkan kinerja tungku krusibel kompak agar lebih efisien.

Bagaimanapun, respon dari SMK yang telah menggunakan tungku krusibel kompak menunjukkan bahwa tungku agak sulit dipindah tempatkan karena bobotnya yang cukup berat. Pemasangan roda juga kurang membantu karena roda cepat rusak akibat bobot tungku berlebih. Inovasi yang akan dilakukan adalah mengurangi bobot dengan mendesain ulang dan memperkecil dimensi tungku. Namun dimensi kowi dibuat tetap agar jumlah aluminium yang dilebur tetap. Ini terkait dengan kebutuhan aluminium cair untuk praktik. Prototipe tungku ini disebut tungku krusibel kompak mini karena desian dasar dan sistem kerjanya sama dengan tungku krusibel kompak, hanya saja dimensinya lebih kecil. Desain ini membuat ruang antara kowi dan dinding dalam lebih sempit sehingga diharapkan laju peleburan juga lebih cepat. Studi ini tentang pembuatan dan pengujian prototipe tungku krusibel kompak mini.

\section{METODE}

Inovasi tungku krusibel kompak mini dilaksanakan dengan tahapan: (1) observasi hasil pengembangan tungku krusibel kompak sebelumnya; (2) Desain tungku krusibel kompak mini; (3) Pembuatan prototipe tungku krusibel kompak mini; (4) Uji coba; (5) Analisis data dan kesimpulan. Seperti tungku krusibel kompak, sumber panas dari LPG dibakar dengan kompor gas tekanan tinggi MIYAKO MH-388. Kowi yang digunakan berdiameter 
luar $170 \mathrm{~mm}$ tebal dinding $8 \mathrm{~mm}$ dan tinggi 250 mm terbuat dari baja karbon, sehingga kapasitas aluminium yang dilebur sama dengan tungku kruibel kompak. Kinerja prototipe tungku krusibel kompak mini ditentukan dari kecepatan peleburan aluminium di dalam kowi, kecepatan kenaikan suhu, kebutuhan gas LPG dan suhu dinding luar tungku. Instrumen untuk merekam kenaikan suhu adalah infrared thermometer. Timbangan digital digunakan untuk menimbang bobot aluminium dan gas LPG. Perubahan suhu di catat setiap 5 menit sampai aluminium mencair. Langkah ini diulangi 3 kali. Set up kompor gas tekanan tinggi dibuat sama untuk 3 kali pengulangan. Selama pengambilan data, tabung gas LPG direndam dalam air panas agar tidak membeku. Meski pengujian dilakukan pada hari yang berbeda, namun pengujian dilakukan pada jam dan tempat yang sama, sehingga kondisi luar sekitar tungku saat pengujian diasumsikan sama karena. Seluruh data pengujian dicatat, di ambil reratnya. Kondisi-kondisi yang terjadi selama uji coba didokumentasi dengan foto-foto. Hasil data disajikan dalam garfik dan dianalisis secara deskriptif dan kemudian diambil kesimpulan.

\section{HASIL DAN PEMBAHASAN}

Inovasi tungku krusibel kompak mini ini terletak pada desain isolator panas pada dinding dalam dan ukuran tungku. Isolator panasnya kombinasi semen castable TNC-17 dan selimut keramik. (Arianto, dkk., 2017c). Namun, tebal semen castable TNC-17 di tungku krusibel kompak mini hanya $20 \mathrm{~mm}$. Konsep inovasi tungku krusibel kompak mini tampak pada Gambar 2, sedang desainnya tampak pada Gambar 3. Tutup atas juga dilapis isolator kombinasi dari semen castable TNC-17 dan selimut keramik. Desain tutup atas dan rangka berturut-turut tampak pada Gambar 4 dan 5 . Kompor gas bertekanan tinggi ditempatkan pada rangka tepat di bawah tungku. Sebuah pengungkit ditambahkan berfungsi untuk menaik-turunkan kompor dan bukan untuk megatur posisi kompor.

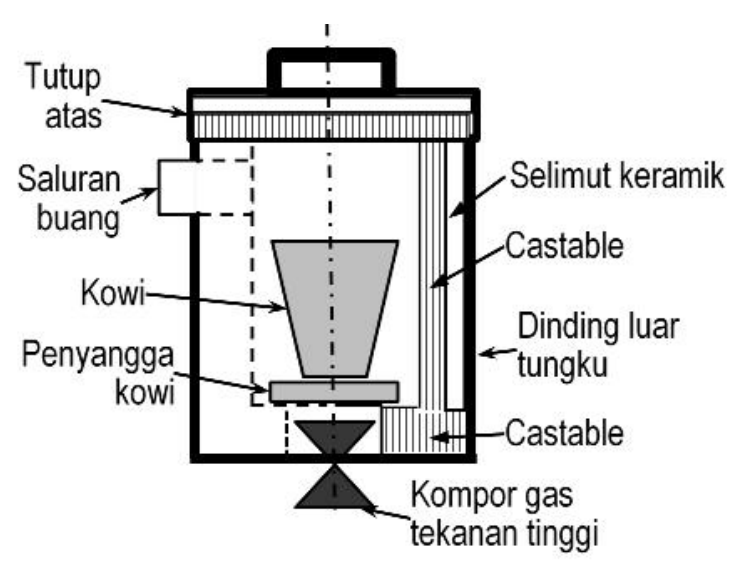

Gambar 2. Konsep tungku krusibel kompak mini.

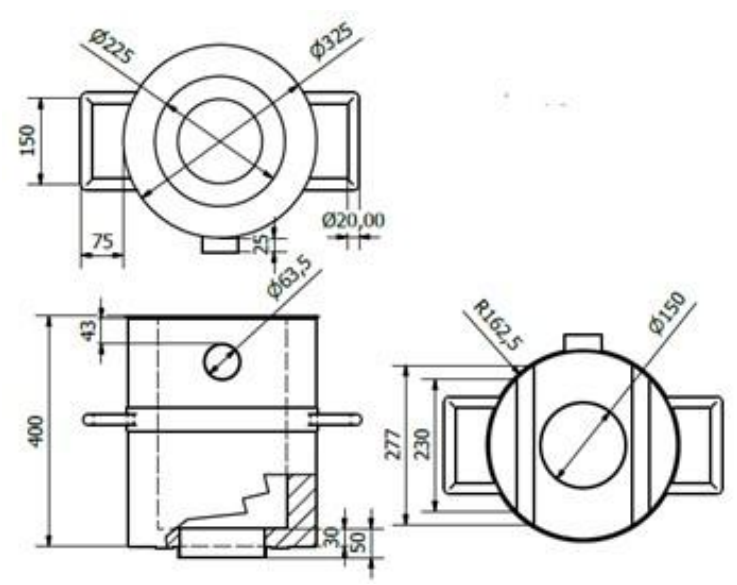

Gambar 3. Desain tungku krusibel kompak mini
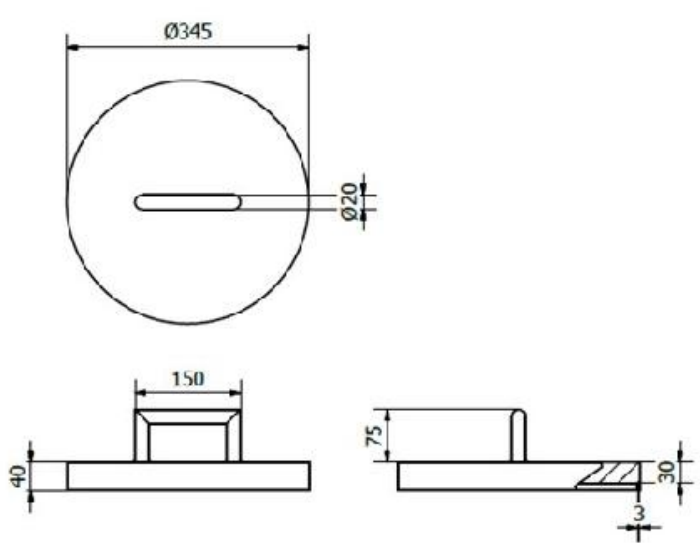

Gambar 4. Desain tutup tungku krusibel kompak mini. 

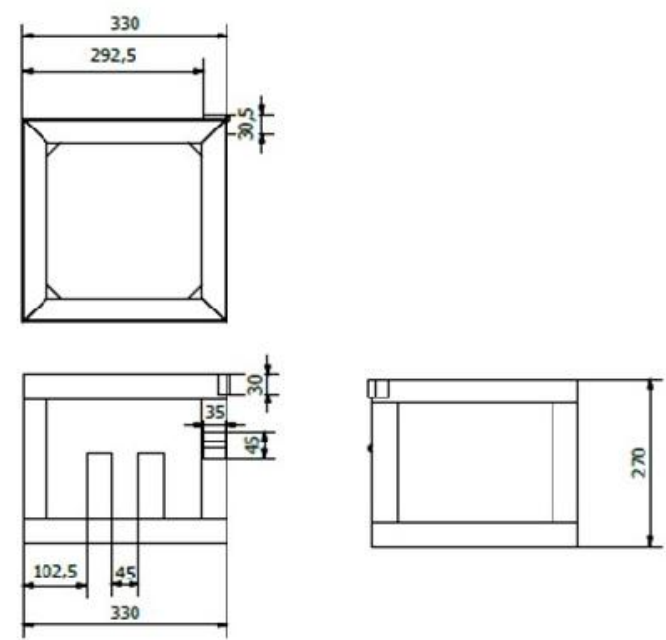

Gambar 5. Desain rangka tungku krusibel kompak mini.

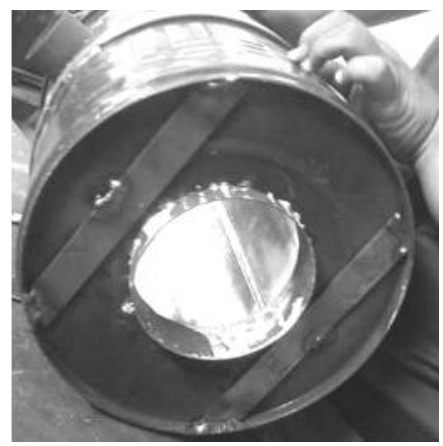

Gambar 6. Penguat di bawah drum.

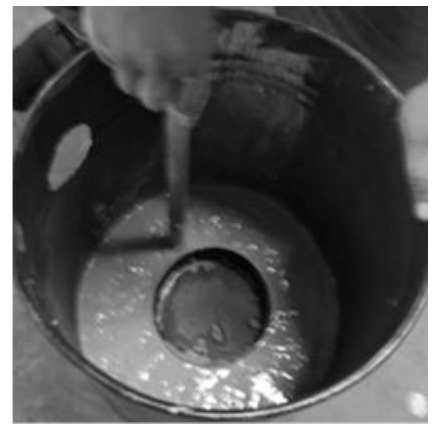

Gambar 7. Pemasangan semen castable di dasar tungku

Tungku dibuat dari sebuah drum bekas berdiameter $325 \mathrm{~mm}$. Drum dipotong setinggi $400 \mathrm{~mm}$ dan pada bagian bawahnya dibuat lubang sesuai desain pada Gambar 2. Dinding drum diberi penguat baja strip yang di rol. Selain sebagai penguat, ini berfungsi untuk menempatkan pegangan tungku. Pada bagian bawah drum terbuat dari plat tipis $0,7 \mathrm{~mm}$ juga ditambahkan pengut dari besi strip (Gambar 6).

Isolator panas tungku menggunakan selimut kaeramik D.96 tebal $20 \mathrm{~mm}$ dan semen castable TNC-17. Mula-mula semen castable di cor didasar drum terlebih dulu. (Gambar 7). Ini sebagai penahan kowi dan dudukannya serta isolator samping. Setelah kering, isolator panas pada dinding samping dipasang. Selimut keramik ditenenpel pada dinding dalam drum. Sebuah plat baja $0,7 \mathrm{~mm}$ di rol dan digunakan sebagai penahan selimut keramik dan pemisah dengan semen castable. Semen catable diberi penguat besi beton diameter $5 \mathrm{~mm}$ (Gambar 8). Penguat tidak menempel pada plat pemisah. Ini berbeda dengan penguat yang digunakan oleh Abed (2013: 113). Kemudian, semen castable di cor pada tungku yang hasilnya tampak pada Gambar 9.

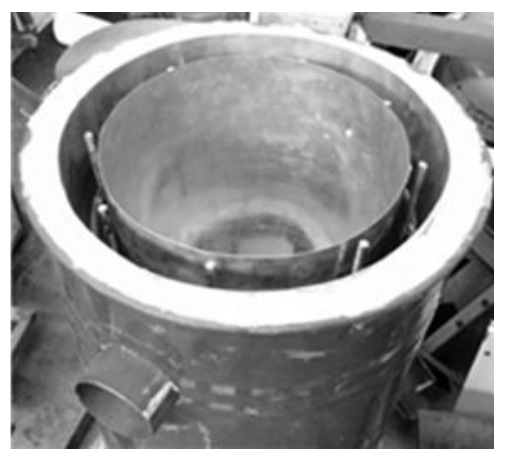

Gambar 8. Pemasangan selimut keramik dan penguat castable.

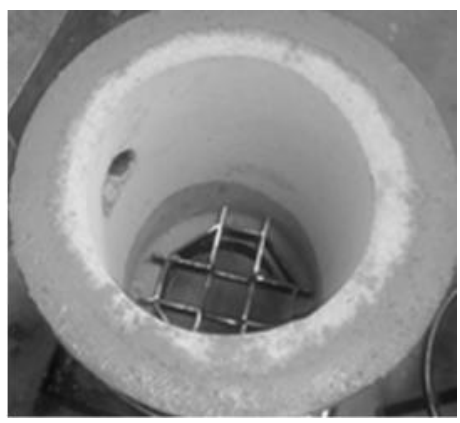

Gambar 9. Isolator panas pada tungku krusibel kompak mini.

Tutup tungku (Gambar 4) dibuat dari plat baja plat baja. Bagian samping dibuat dari plat baja tebal $1 \mathrm{~mm}$ dan di rol, sedang bagian atas dibuat dari palt baja tebal $3 \mathrm{~mm}$. kedua bagian 
disatukan dengan pengelasan. Seperti tungku, tutup atas diberi isolator selimut keraik dan semen castable TNC-17. Penguat castable TNC-17 dibuat dari besi beton diameter $5 \mathrm{~mm}$ yang di las ke bagian saping tutup.

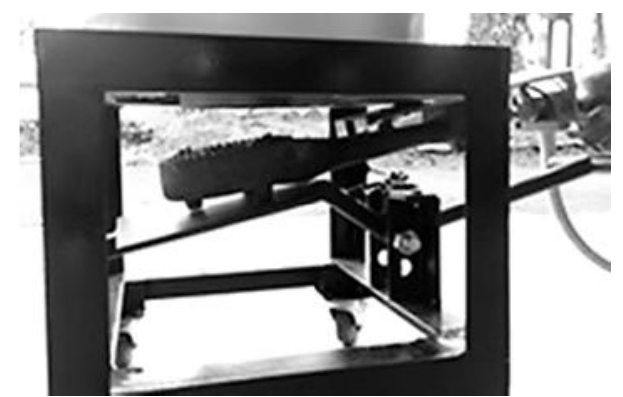

Gambar 10. Mekanisme pengungkit untuk menaik-turunkan kompor.

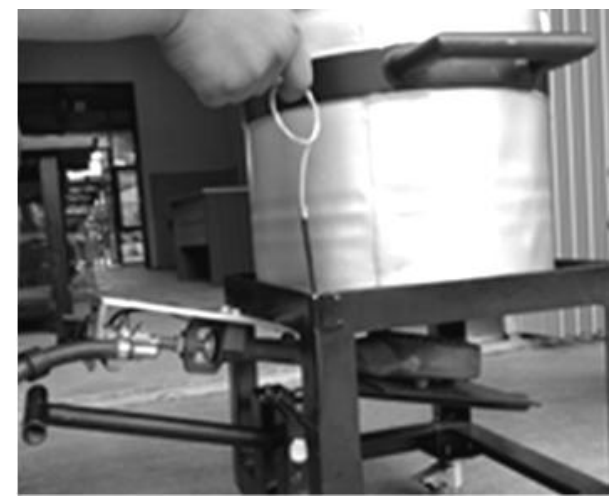

Gambar 11. Kabel pelepas kunci kait meknisme pengungkit.

Rangka tungku dibuat dari baja profil siku (40x40x3) mm. Rangka dilengkapi 4 buah roda sehingga tungku lebih mudah dipindah tempatkan. Kompor ditempatkan pada sebuah pengungkit. Ini berfungsi untuk menaikkan kompor saat proses peleburan dan menurunkan kompor saat mengambil aluminium cair.. Pada saat itu kompor harus dimatikan agar operatot terhindar dari api yang menyembur dari kompor. Saat kompor dimatikan, posisinya harus diturunkan agar kompor terhindar dari panas berlebih dari tungku. Ini agar umur pakai kompor lebih lama. Pengungkit untuk menaikkan kompor tampak pada Gambar 10. Sebuah pengunci kait digunakan untuk menahan pengungkit agar kompor tetap pada posisi naik. Kompor diturunkan dengan melepas pengait yang terhubung dengan sebuah kabel pelepas. (Gambar 11).

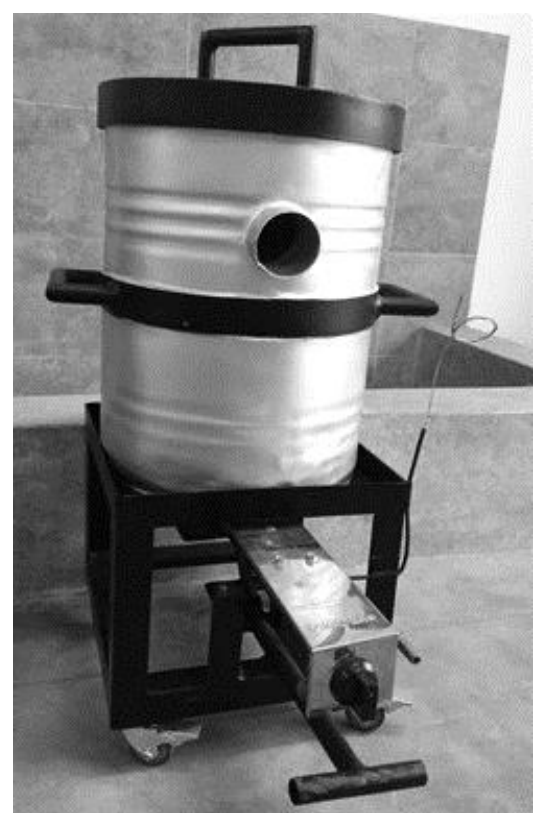

Gabar 12. Tungku kusibel kompak mini.

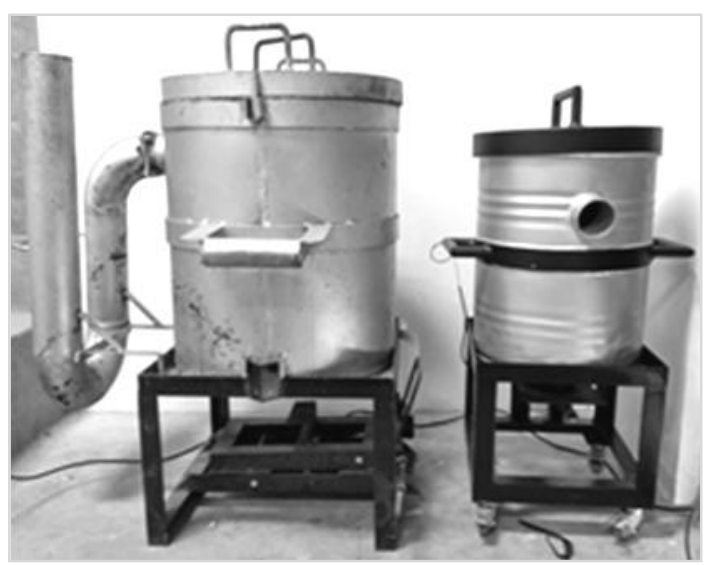

Gambar 13. Perbandingan tungku krusibel kompak (kiri) dan tungku krussibel kompak mini (kanan).

Dimensi keseluruhan tungku krusibel kompak mini adalah (330x330x750) mm. (Gambar 12). Bobot total tungku kusibel kompak mini adalah $46 \mathrm{~kg}$ dan bobot tungku saja $29 \mathrm{~kg}$. Ini berarti, secara keseluruhan tungku kusibel kompak mini lebih ringan 64\% dari tungku kusibel kompak, sedang bobot tungkunya lebih ringan 67\%. Gambar 13 memperlihatkan perbandingan ukuran tungku krusibel kompak mini dan tungku krusibel 
kompak, sedang perbandingan ruang pemanasnya ditunjukkan pada Gambar 14.

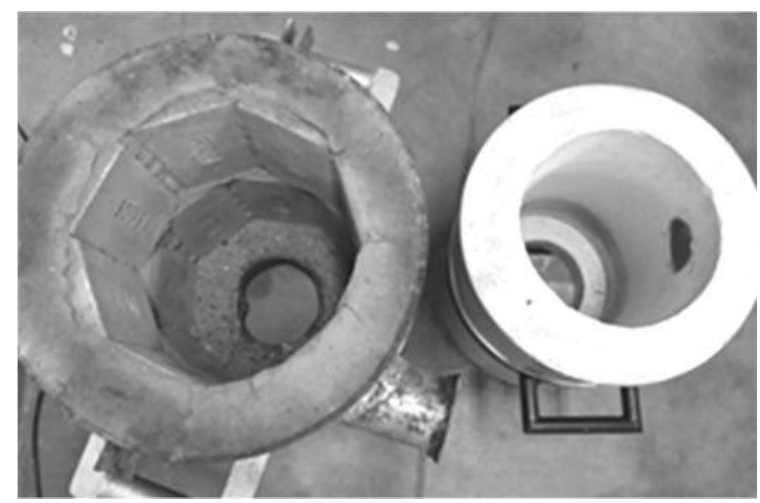

Gambar 14. Perbandingan ruang pemanas tungku krusibel kompak (kiri) dan tungku krusibel kompak mini (kanan).

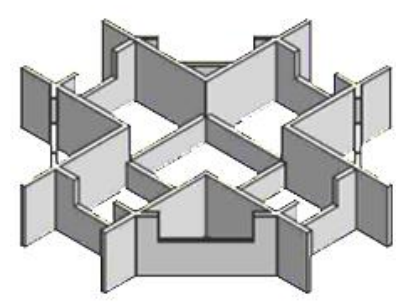

Gambar 15. Penyangga kowi.

Penyangga kowi pada tungku kruibel kompak mini tampak pada Gambar 15. Pada penyangga terdapat alur-alur yang berfungsi mengurangi aliran balik api saat membentur kowi. Aliran api yang membentur kowi akan berbelok ke samping, kemudian bergerak sepanjang dinding kowi. Panas dari api akan merambat melalui dinding kowi menuju ke aluminium.

Performa tungku krusibel kompak mini ditentukan dari perubahan suhu saat tungku beroperasi. Pengukuran perubahan suhu dilakukan pada kowi (Gambar 16) dan pada dinding luar (Gambar 17). Sedang pada gambar 18 dan 19 tampak perubahan suhu saat tungku di uji coba.

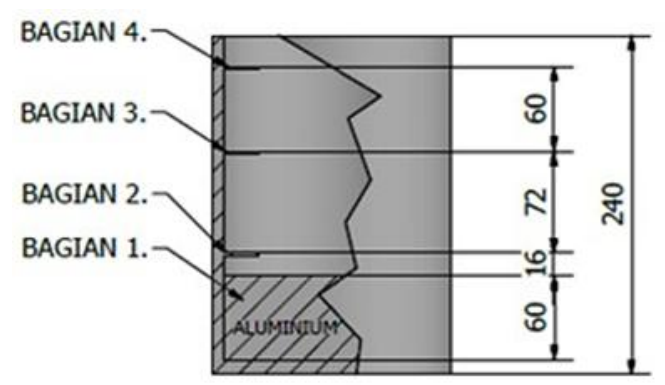

Gambar 16. Bagian-bagian kowi yang di ukur suhunya.

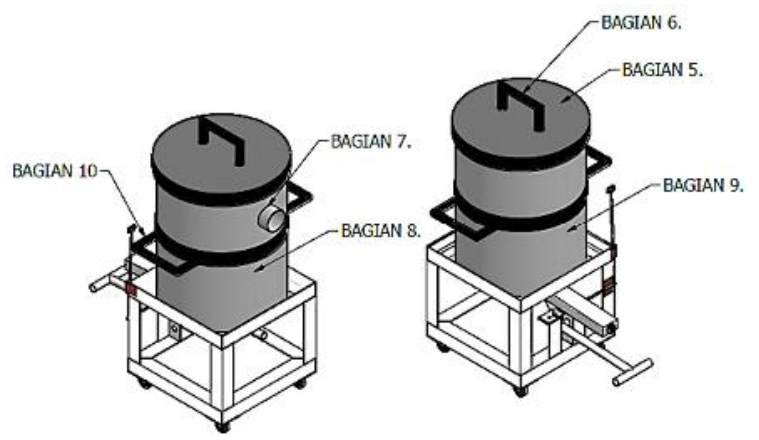

Gambar 17. Bagian-bagian dinding luar yang diukur suhunya

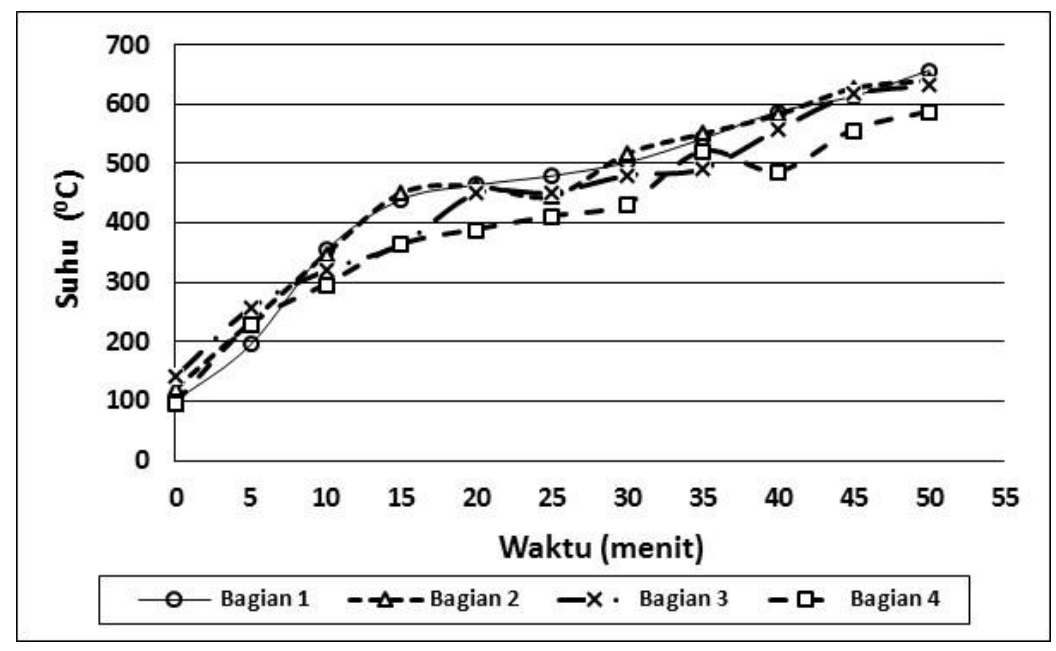

Gambar 18. Perubahan suhu pada kowi 


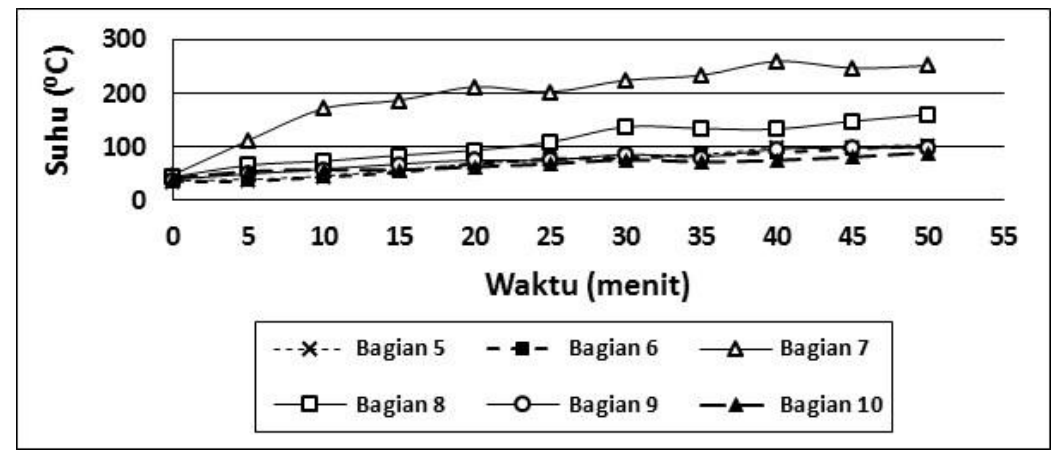

Gambar 19. Perubahan suhu pada dinding luar tungku.

Gambar 18 menunjukkan perubahan suhu kowi saat uji coba. Perubahan suhu pada tiap bagian kowi yang diamati relatif sama. Ini berarti ruang pemanas tungku yang kecil menghasilkan penyebaran panas yang lebih merata. Bagaimanapun, pada bagian 4, suhu yang dicapai saat 50 menit lebih rendah, sedang pada bagian 1, mencapai suhu paling tinggi. Ini menunjukkan bahwa panas merambat dari bawah ke atas. Celah yang sempit antara kowi dan dinding dalam kowi (Gambar 20) menjadikan panas dari kompor lebih fokus dan terarah. Efisiensi panas dari prototipe tungku krusibel kompak mini masih dapat di tingkatkan. Penambahan sirip pada dinding kowi dapat meningkatkan efisiensi perpindahan panas yang sudah terfokus ini. (Arianto, dkk, 2018: 0300661; Arianto, dkk, 2018; Tanaka, 2001).

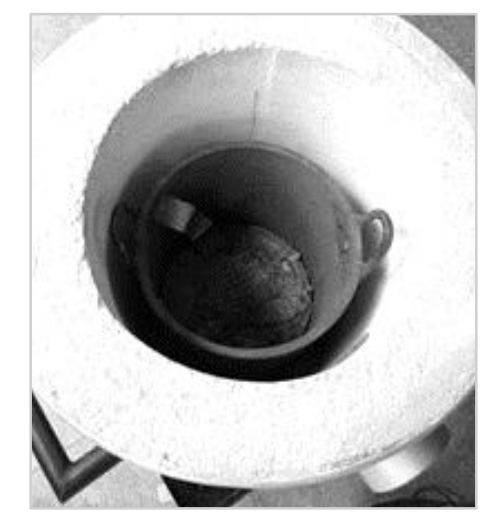

Gambar 20. Celah antara kowi dan dinding dalam tungku.

Gambar 19 menunjukkan perubahan suhu dinding luar tungku. Suhu dinding luar sampai 50 menit masih cukup aman, yaitu rata-rata dibawah $100{ }^{\circ} \mathrm{C}$. Tentu saja saat mengopersikan tungku, alat pelindung diri (APD) wajib digunakan. Bagaimanapun, suhu pada bagian 7 dan 8, yaitu saluran pembuangan sisa pembakaran LPG dan sekitarnya terukur diatas $100{ }^{\circ} \mathrm{C}$, tapi masih dibawah $300{ }^{\circ} \mathrm{C}$. Ini wajar karena panas tinggi keluar dari bagian 7 dan merambat ke sekitarnya. Isolator panas yang merupakan kombinasi dari selimut keramik dan castble mampu mengisolasi panas hasil pembakaran LPG di dalam ruang pemanas tungku. Kombinasi isolator ini mampu mengurangi bobot tungku secra signifikan.

Waktu yang dibutuhkan tungku untuk mencapai suhu lebur aluminium tercatat 50 menit. Ini tidak sesuai harapan karena sama dengan tungku krusibel kompak (Arianto, dkk, 2017b: 281). Pengamatan pada Gambar 21 menunjukkan terdapat aliran balik api di bagian bawah tungku dan semburan api yang keluar dari saluran buang. Ini menyebabkan efisiensi panas prototipe tungku krusibel kompak buruk. Energi panas banyak hilang bersama semburan api keluar dan aliran api balik. Tekanan gas yang tinggi dibutuhkan agar dapat tercapai suhu lebur aluminium, namun ini menyebabkan panas terdorong keluar. Fenomena ini sama seperti yang terjadi pada tungku dengan aliran udara paksa (Joko, 2013: 52). Perbedaannya adalah pada tungku dengan aliran udara paksa rugi panas disebabkan tekanan blower, sedang pada prototipe tungku krusibel kompak mini disebabkan oleh tekanan gas yang tinggi.

Panas yang hilang lewat saluran buang dapat diatasi dengan economizer seperti yang 
telah dilakukan oleh Arianto, dkk (2017c: 23). Economizer ini adalah saluran buang yang dibuat memanjang dan berbelok, telah terbukti dapat memperbaiki efisiensi tungku krusibel. Selain itu, economizer menjadikan tungku lebih aman, karena semuburan api diarahkan sehingga yang keluar dari saluran buang hanya gas sisa pembakaran LPG. Meski demikian, saat diuji coba, prototipe tungku krusibel kompak mini ini hanya membutuhkan $1,76 \mathrm{~kg}$ LPG untuk mencapai suhu $660{ }^{\circ} \mathrm{C}$ dalam waktu 50 menit. Ini setara dengan kebutuhan LPG tungku keusibel kompak. Bagaimanapun, economizer perlu diaplikasikan pada prototipe tungku krusibel kompak mini untuk memperbaiki efisiensi panas dan meningkatkan keamanan.

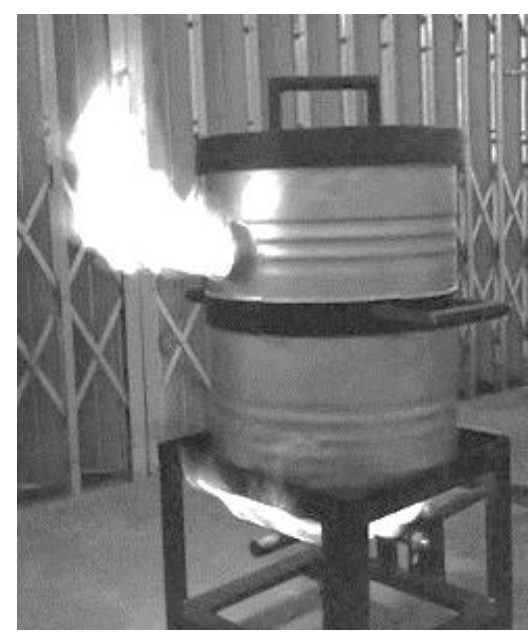

Gambar 21. Api yang keluar dari saluran buang dan saluran masuk.

Aliran api balik dari terjadi akibat semburan api dari kompor gas tekanan tinggi yang membentur kowi. Hal ini dapat diatasi dengan menentukan kedudukan kowi yang optimal seperti yang dilakukan oleh Arianto, dkk. (2018b). Selain itu, diamater kowi yang optimal juga perlu ditelaah lebih lanjut sehingga aliran balik api dapat di minimalkan. Namun demikian, kapasitas kowi tetep dipertimbangkan sama dengan kapasitas kowi pada tungku krusibel kompak. Perbandingan diameter dan tinggi kowi harus ditentukan untuk mencapai hal tersebut.

\section{SIMPULAN}

Prototipe tungku krusibel kompak mini berdimensi (330x330x750) mm dengan bobot total $46 \mathrm{~kg}$. Tungku dapat dibuat dari drum bekas dengan isolator panas kombinasi dari selimut keramik D.96 dan castable TNC-17. Prototipe tungku mampu melelehkan $3 \mathrm{~kg}$ aluminium dan mencapai suhu $660{ }^{\circ} \mathrm{C}$ dalam 50 menit dengan kebutuhan LPG $1,76 \mathrm{~kg}$. Suhu dinding luar tungku masih dalam batas aman saat dioperasikan. Prototipe tungku krusibel kompak mini perlu dikembangkan lebih lanjut untuk memperbaiki efisiensi panasnya.

\section{DAFTAR RUJUKAN}

Abed, E.J. 2013. Manufacture and Performance of Gas Furnace, International Journal Metallurgical \& Materials Science and Engineering (IJMMSE), 3(1), 109-118.

Alaya F.H.M., Didik A., Yanuar T.S., M. Ammar R., Zainal A., dan Yuliyanti. 2016. Pengujian Awal Kinerja Tungku Pengecoran Logam Alumunium Matrix Composite Dengan Bahan Bakar Gas LPG. Rotasi. 18(4), 110-116.

Amir Zaki Mubarak dan Akhyar. 2013. Perancangan dan Pembuatan Dapur Peleburan Logam dengan Menggunakan Bahan Bakar Gas (LPG), Jurnal Teknik Mesin Unsyiah, 1(3), 128-132.

Tiwan, Arianto L.S., Widarto dan Aan A. 2017. Aluminum Casting Laboratory. Proceedings of the International Conference on Technology and Vocational Teachers, vol 102 (Yogyakarta: Faculty of Engineering/Yogyakarta State University/ Atlantis Press/doi.org/10.2991/ictvt17.2017.37), 218-222.

Arianto L.S., Tiwan, Widarto, Aan A. 2017a, Tungku Krusibel Kompak, Paten Indonesia, No. S00201706161. 
Arianto L.S., Tiwan, Sutopo dan Nurdjito,. 2017b. Sarana Praktik Pengecoran Aluminium Untuk SMK Program Keahlian Teknik Mesin, Prosiding Seminar Nasional Pendidikan Vokasional (SNPV) 2017, tanggal 6 Februari 2017, 277-284, Yogyakarta: FT UNY.

Arianto L.S., Tiwan, Mujiyono. 2017c. Tungku Krusibel dengan Economizer untuk Praktik Pengecoran di Jurusan Pendidikan Teknik Mesin FT UNY, Jurnal Dinamika Vokasional Teknik Mesin, 2(1), 21-27.

Arianto L.S., Tiwan, Widarto, and Aan Ardian, 2018, Spiral Finned Crucible Pot, Proceeding of $3^{\text {rd }}$. International Conference on Industrial, Mechanical, Electrical, and Chemical Engineering, (Surakarta) vol 1931 (America: A N Agung et all AIP) p 030066-1

Arianto L.S., Tiwan, Widarto dan Aan A. (2018a), Improving the compact crucible furnace performance by adding fins in heating chamber, The 2nd International Conference on Technology and Vocational Teachers, 15 November 2018, Yogyakarta, FT UNY.

Arianto L.S. dan Achmad Arifin. (2018b). Optimizing performance of compact crucible furnace by optimizing position of crucible pot, International Conferene on Vocational Education of Mechanical and Automotive Technology, 20 October 2018, Yogyakarta, FT UNY.

Chukwudi, B.C. and Ogunedo, M.B. 2017. Design and Development of a Gas Fired Reverberatory Furnace: In View of Huge Gas Reserves in Nigeria, The Pacific Journal of Science and Technology, 18(1), 13-21.

Chukwudi, B.C. and Ogunedo, M.B. 2018. Design and Construction of an Oil Fired Crucible Furnace. International Journal of Research and Review (IJRR), 5(2), 6774.

Eko W., Agus Y., dan Agung S.D. 2012. Redesain Dapur Krusibel dan Penggunaannya untuk Mengetahui Pengaruh Pemakaian Pasir Resin pada Cetakan Centrifugal Casting, Jurnal Foundry, 2(1), 24-30.

Ella Sundari. 2011. Rancang Bangun Dapur Peleburan Alumunium Bahan Bakar Gas, Jurnal Austenit, 3 (1), 17-26.

Ighodalo, O.A., Akue, G., Enaboifo, E. and Oyedoh, J. 2011. Performance evaluation of the local charcoal-fired furnace for recycling aluminium. Journal of Emerging Trends in Engineering and Applied Sciences (JETEAS). 2 (3), 448450.

Ikechukwu G.A. and Atanmo P.N. 2018. Development of an Improved Crucible Furnace Using Locally Sourced Materials for Teaching and Learning Purposes in Metallurgical Laboratory, Current Journal of Applied Science and Technology, 26(1), 1-14.

Joko W. 2013. Rancang Bangun Tungku Peleburan Aluminium Berbahan Bakar Padat Dengan Sistem Aliran Udara Paksa, Jurnal Teknik. 2(2), 47-53.

Olalerel, A.A., Dahunsi, O.A., Akintunde, M.A. and Tanimola M.O. 2015. Development of a crucible furnace fired with spent engine oil using locally sourced materials, International Journal of Innovation and Applied Studies, 13(2), 281-288.

Tanaka A, Tsuri M, Ando H, Kikura M and Ueki M. 2001. High efficeincy crucible melting furnace for non-ferrous metals diakses 10 Agustus 2017 dari: http://www.htechno.com/en/seihin/asm.html. 